\title{
Public health nurses' perceptions of health literacy in adolescent patients
}

\author{
Leslie J. Malloy-Weir *1, Deborah Begoray², Jan Tatlock ${ }^{3}$ \\ ${ }^{1}$ College of Medicine, University of Saskatchewan, Saskatoon, Saskatchewan, Canada \\ ${ }^{2}$ Faculty of Education, University of Victoria, Victoria, British Columbia, Canada \\ ${ }^{3}$ Vancouver Island Health Authority, Nanaimo, British Columbia, Canada
}

Received: February 26, 2016

DOI: $10.5430 /$ jnep.v6n11p1
Accepted: May 29, 2016

Online Published: June 21, 2016

\begin{abstract}
Purpose: To obtain and document public health nurses' thoughts about health literacy and the method(s) they used to communicate with adolescent patients.

Methods: Using a qualitative descriptive approach, we conducted semi-structured interviews with a purposeful sample of public health nurses working with adolescents, either part- or full-time. Emerging themes were identified using content analysis and confirmed by two health literacy researchers and a public health nurse.

Results: Nurses ascribed different meanings to the term health literacy, the most common being an understanding of one's health or health-related information. They provided various types of health information to adolescent patients, used more than one mode of communication, and assessed adolescents' understanding primarily by asking questions. Tailored approaches employed by nurses to communicate information to adolescents included the use of peer educators in schools; business cards with information on where to seek more information; and text messaging. These approaches, however, were not uniformly adopted and some nurses expressed concerns about the lack of security associated with the use of text messaging. Anxiety/fear in adolescents emerged as a prominent patient-related barrier to effective communication and stemmed, in some cases, from adolescents' lack of understanding about confidentiality policies. Major provider-related barriers to effective communication included hours and locations of services that were inconvenient for adolescents, and limited time to spend with adolescent patients.

Conclusions: Attention is needed to patient- and provider-related barriers that may limit or impeded efforts by public health nurses to promote health literacy in adolescent patients.
\end{abstract}

Key Words: Health literacy, Adolescent, Public health nursing

\section{INTRODUCTION}

Adolescence is the period of human growth and development that occurs between the ages of 10 and 19. ${ }^{[1]}$ This period of human development is characterized by rapid biological and psychosocial changes $^{[2]}$ and the acquisition of skills needed to engage in adult relationships and roles. ${ }^{[1]}$ During this period, adolescents cannot fully comprehend relationships between behaviour and consequences. ${ }^{[1]}$ They also lack understanding about the extent to which they have control over health-related decision making. This lack of understanding, in combination with social pressures, makes adolescents vulnerable to developing high-risk behaviours that may persist into adulthood and have lasting impacts on health. ${ }^{[2]}$

*Correspondence: Leslie J. Malloy-Weir; Email: Imalloyw@gmail.com; Address: 104 Clinic Place, University of Saskatchewan, Saskatoon, Saskatchewan, S7N 5E5, Canada. 
While generally considered to be healthy, adolescents worldwide struggle with a variety of health problems (e.g., sexually transmitted infections, mental health problems, alcohol and substance abuse, obesity) for which they may not seek, nor receive, adequate treatment. In 2012, approximately 1.3 million adolescents died; primarily, from preventable or treatable diseases. ${ }^{[3]}$ This finding requires health care providers to be both sensitive and responsive to the health struggles that adolescents face.

The need for health care providers to approach adolescents as unique individuals with, among other things, differing levels of health literacy is part of the World Health Organization' ${ }^{[4]}$ core competencies for effective communication with adolescents. Elsewhere, the promotion of health literacy defined as "the cognitive and social skills which determine the motivation and ability of individuals to gain access to, understand and use information in ways which promote and maintain good health" (para 1) ${ }^{[5]}$ - has been identified as one way to prevent negative health outcomes in adolescents ${ }^{[6]}$ and prepare adolescents to be active participants in their care. ${ }^{[7]}$

Health literacy has also been identified as a public health goal $^{[8,9]}$ and tools exist to help public health professionals integrate health literacy into their daily practice. ${ }^{[10,11]}$ There is a paucity of research, however, on public health nurses' understanding and promotion of health literacy in adolescent patients. To address this gap, we sought to obtain and document public health nurses' thoughts about health literacy and the method(s) they used to communicate with adolescent patients.

\section{Methods}

We adopted a qualitative descriptive approach ${ }^{[12,13]}$ because of its emphasis on "obtaining straight and largely unadorned (i.e., minimally theorized or otherwise transformed or spun) answers to questions of special relevance to practitioners and policymakers" (p337). ${ }^{[12]}$ All procedures were approved by the University of Victoria/Vancouver Island Health Authority Joint Research Ethics Board.

Recruitment in our study was facilitated by an administrative assistant who e-mailed an invitation to participate to a purposeful sample of public health nurses working, either partor full-time, with adolescents in British Columbia, Canada. Nurses wishing to participate e-mailed the first or second author to arrange a telephone interview at their convenience. Nine nurses responded to the invitation and agreed to participate in our study. Although this number was lower than expected, we were able to achieve saturation due to the homogeneity of our sample.

Nurses were allowed paid time off during working hours 2 to participate in our study, but were not otherwise compensated. Interviews were conducted by the first author between March, 2015 and June, 2015 and each lasted approximately 30 minutes. A semi-structured interview guide, which had been pilot tested with a public health nurse working with adolescents, was used in all interviews. Verbal consent was obtained from all nurses prior to their participation. All interviews were digitally recorded and transcribed verbatim. Identifiers were removed from the data to ensure the anonymity of nurses and to preserve confidentiality.

Content analysis, using a template analysis style, ${ }^{[14]}$ was employed by the first author (a health literacy researcher with training and experience in qualitative research methods) to identify emerging themes. These themes were both reviewed and confirmed by the second author (a health literacy researcher with training and experience in conducting qualitative research) and the third author (a public health nurse possessing in-depth knowledge of the context, but not involved in the collection of the data).

\section{RESULTS}

All of the nurses were female and worked with adolescents, either part- or full-time, in youth clinics and/or high schools. Six of the nurses had more than 10 years of experience working with adolescents in practice.

\subsection{Thoughts about health literacy in adolescents}

Nurses ascribed multiple and differing meanings to the term health literacy, the most common being an understanding of one's health or health-related information: "It means the understanding... like, if a client understands what we, as health professionals, we are conveying to them... and do they fully understand..." (PHN \#9). When asked about health literacyrelated difficulties in adolescent patients, a range of responses were given (see Table 1). Adolescents were, however, most frequently perceived by nurses to have difficulties evaluating health information in terms of its credibility and source.

Table 1. Public health nurses' perceptions of health literacy-related difficulties in adolescent patients

\begin{tabular}{ll}
\hline $\begin{array}{l}\text { “Approximately, what percentage of the adolescents } \\
\text { that you work with on a daily basis has difficulty” }\end{array}$ & $\begin{array}{l}\text { Mean \% } \\
\text { (SD) }\end{array}$ \\
\hline $\begin{array}{l}\text { Obtaining or accessing information } \\
\text { Understanding health information }\end{array}$ & $57.7(31.0)$ \\
Communicating health information & $55.1(25.1)$ \\
$\begin{array}{l}\text { Evaluating health information in terms of its credibility, } \\
\text { or source }\end{array}$ & $66.4(26.1)$ \\
Using or acting on health information & $55.8(23.8)$ \\
\hline
\end{tabular}

\subsection{Communication practices with adolescent patients}

All of the nurses routinely provided more than one type of health information to adolescent patients. Health infor-

ISSN 1925-4040 E-ISSN 1925-4059 
mation topics ranged from nutrition, sexual health, alcohol and drug use, general health and wellness, mental health, harm reduction, immunizations, and parenting. Some nurses communicated primarily verbal information to adolescent patients, while others reported a 50/50 split between verbal and written information, and/or the use of "hands on" techniques:

I am verbally going through things, but I am having them [adolescents] read it, and when it comes to hands on, I would do a hands on opening a birth control package. Making sure that they handle it, understand what to do, or whatever type of birth control they have chosen. So actually if would be tactile, verbal, and reading the written word with us. (PHN \#3)

Five nurses reported referring adolescent patients to trustworthy web-based resources. This practice allowed adolescents to obtain additional information on their own, and, in some cases, saved time: "I try to encourage websites that they can go to for good information so that they can go in and find what they need to do in way that is quicker than coming into a physical clinic" (PHN \#8).

When asked if the written information they provided to adolescents was in plain language, five nurses stated it was. Two nurses reported that most, but not all, of the written information was in plain language, and two nurses were not sure. In Table 2, the tailored approaches used by nurses to communicate health information to adolescent patients are listed (i.e., peer educators, business cards, text-messaging). These approaches, however, were not uniformly adopted across nurses and some nurses expressed concerns about the use of text messaging.

Table 2. Tailoured approaches used by nurses to communicate health information to adolescents

\begin{tabular}{|c|c|}
\hline Tailoured communication & Illustrative quotes \\
\hline Peer educators & $\begin{array}{l}\text { "Having youth speaking to youth [peer educators] is what has been a great bonus so that they understand that it } \\
\text { isn't just us in the health field. It's their fellow peers that are in there talking this talk, making it very acceptable to } \\
\text { discuss sexual health and sexually transmitted infections and so on. So I think it's actually making sure that they } \\
\text { understand they are getting some of that education and learning from their own peers. And, that has been a great } \\
\text { bonus, I think, in terms of communicating with them." (PHN\#3) }\end{array}$ \\
\hline Business cards & $\begin{array}{l}\text { "What we have found is, the large print copy that we go over...say, for instance, someone is starting on birth } \\
\text { control, we find that large print copy they don't like to take because it is not discrete enough. So we have business } \\
\text { card sized versions - what we review with them - on a lot of different topics... it's more discrete for them when } \\
\text { they are taking it home.” (PHN \#5) }\end{array}$ \\
\hline Text-messaging & $\begin{array}{l}\text { “Some of the youth don't have any other mode of contact so they don't have a voice plan on a phone. They don't } \\
\text { have access to a computer. They don't have data on their phone, but they have texting capabilities. Most texting is } \\
\text { generally related to scheduling appointments. We try to let them know that this isn't secure and you may not know } \\
\text { who may be holding the phone...Even saying that, some of the clients will text stuff that I am kind of like, okay } \\
\text { now we are getting into an area where it is not really general information, and I will usually stop the conversation at } \\
\text { that point and say, "Can we talk about this in person?” Or, if that person happens to have another mode of contact, } \\
\text { I will say, “Can I call you and have a conversation over the phone?” (PHN \#1) }\end{array}$ \\
\hline
\end{tabular}

\subsection{Assessing comprehension of health information in adolescent patients}

Nurses in our study routinely assessed adolescent patients' understanding of health information, in initial and/or followup visits, by asking a series of questions (e.g., Do you understand what I am saying? What would you do in this situation? What are the major points that I wanted to make sure you remembered? Do you have any questions?), or asking adolescents to explain how they would, for example, take their birth control. By doing so, nurses could assess whether, or not, they had communicated information clearly:

I will ask a question so that I get their level of understanding. So, "Can you explain to me how you take your birth control?"..."Can you tell me about the serious side effects that I'm concerned with?" Rather than me just telling them again, I want to hear it in their words. You learn when you work with youth....oh! I thought I was clear, and I wasn't. That is also where you will pick up on their comprehension. (PHN \#4)

\subsection{Barriers to effective communication}

The patient- and provider-related barriers to effective communication with adolescent patients that were identified by nurses are shown in Table 3. Anxiety/fear in adolescents (e.g., fear of family finding out, fear of unknown, fear of disclosure, fear of asking questions) emerged as a prominent patient-related barrier and, in some cases, stemmed from a lack of understanding of confidentiality policies:

So people [adolescents] will be worried, won't come to a place to get information because they might get in trouble from a parent thinking that they are going to be, or are, sexually active could be a really clear example because 
they have been told by their parent, if you are sexually active, we are going to boot you out of the house... yes, in this day and age, I still hear that. Or, they want an alcoholic drug counselor, or they don't want a parent to know, or somebody to know, that they are actually using drugs and that sort of thing. (PHN \#4)

Multiple provider-related barriers to effective communication were also identified by nurses (see Table 3 ). One nurse reported, "the biggest barrier is access to service. My hours, $8: 30$ to $4: 00$, is not very conducive to providing access" (PHN \#8). She further stated:

Geographical aspect would be the most problematic because, mostly in my experience with youth, when they have a concern they want access right away. Otherwise the concern may be forgotten about so, if you have to hike across town to find out information, or if you have to wait until four and then get back to your community and, hopefully, the nurse is still there. It's not really timely. (PHN \#8)

\subsection{Facilitators of effective communication}

Facilitators of effective communication with adolescent patients are shown in Table 3. These facilitators include adolescent-friendly attitudes and behaviours and services that are easily accessed. One nurse reported, "[B]eing within the schools has helped because then we are not relying on them coming to us. We are going to them and that seems to make accessibility easier for them and they are able to come more" (PHN \#7). Another nurse highlighted the importance of training: "[W]e have had a lot of training on how to effectively communicate. We have taken motivational interviewing. We have had a number of workshops on that... on how to essentially ask questions and facilitate change. That's been helpful" (PHN \#1).

Table 3. Barriers and facilitators to effective communication with adolescent patients

\begin{tabular}{|c|c|}
\hline Barriers & Facilitators \\
\hline $\begin{array}{l}\text { Patient-related barriers: } \\
\text { - } \quad \text { adolescent fear/anxiety about the unknown; family members } \\
\text { finding out; asking questions or admitting that they don’t } \\
\text { understand; and disclosure (lack of understanding about } \\
\text { confidentiality policies) } \\
\text { - } \quad \text { lack of trust or established relationship with health care provider } \\
\text { - } \quad \text { having a friend in the room (giggling, not wanting to share } \\
\text { - } \quad \text { health concern) } \\
\text { - } \quad \text { inability to articulate what is happening } \\
\text { belief in false information obtained from family, friends, or the } \\
\text { - Internet } \\
\text { low literacy }\end{array}$ & $\begin{array}{l}\text { Provider-related facilitators: } \\
\text { - } \quad \text { adjusting language to meet the level of adolescents } \\
\text { - } \quad \text { avoiding lecturing/preaching/bossing } \\
\text { - } \quad \text { being open and listening } \\
\text { - } \quad \text { being interested } \\
\text { - } \quad \text { being warm } \\
\text { - } \quad \text { being aware of concerns and showing empathy } \\
\text { - } \quad \text { giving praise } \\
\text { - } \quad \text { giving encouragement } \\
\text { - } \quad \text { making adolescents comfortable } \\
\text { - } \quad \text { providing easy access to services } \\
\text { - } \text { showing respect }\end{array}$ \\
\hline $\begin{array}{l}\text { Provider-related barriers: } \\
\text { - } \quad \text { lack of sensitivity to adolescents } \\
\text { - } \quad \text { physical location of services does not provide enough privacy } \\
\text { - } \quad \text { inconvenient hours of services } \\
\text { - } \quad \text { inability of nurses to respond to text messages fast enough } \\
\text { - lack of computers and time to go over websites with adolescents }\end{array}$ & \\
\hline
\end{tabular}

\section{Discussion}

We sought to obtain and document public health nurses' thoughts about health literacy and the method(s) they used to communicate with adolescent patients. Nurses in our study attributed variable meanings to health literacy in adolescents, the most common being the understanding of one's health or health-related information. This finding is not surprising given the lack of agreement over the definition of health literacy in the academic literature, ${ }^{[15]}$ and the emphasis that public health nurses, in our study, placed on patient understanding. The wide range in nurses' perceptions of the health literacy-related difficulties faced by adolescents is also not surprising given that adolescent capacities - including health literacy skills - evolve with age and experience. ${ }^{[6]}$

In comparing our findings with recommendations made in the pediatric literature for the promotion of health literacy in 
patient care settings, ${ }^{[8]}$ we found both alignment and divergence. To promote health literacy, recommendations include health communication training (i.e., emphasizing "teachback", reduced use of jargon, effective use informational materials, motivational interviewing, and shared decisionmaking); the use of simplified print materials; and use of technology for the delivery of health information. ${ }^{[8]} \mathrm{Al}-$ though nurses in our study did not explicitly use the term "teach-back", they did report asking adolescent patients to explain how they would use, for example, a method of birth control. One of the nurses also reported that she, along with other nurses, had received a lot of communication training, including training on the use of motivational interviewing. In previous research, motivational interviewing has been identified as a way to promote health literacy in patients ${ }^{[17]}$ and bring about health behaviour change in adolescents. ${ }^{[16,18]}$

With respect to the use of simplified print materials, nurses in our study understood the reluctance of adolescents to take sensitive information in large paper formats and, instead, provided business cards with pertinent information. Approximately half of the nurses also reported the provision of written information in plain language. Opportunities for nurses to learn how to both identify, and develop, plain language resources for adolescents would increase the consistency of this practice. Published guidelines recommend that patients be involved in the selection, design, and evaluation of print-based resources. ${ }^{[19]}$ The involvement of adolescents, using short surveys and informal interviews, ${ }^{[19]}$ would help to ensure that the resources used by public health nurses are readable, comprehensible, appropriate and acceptable to their intended audience.

In regard to the use of technology, some of the nurses reported referring adolescents to trustworthy websites. This practice is beneficial to adolescents that have difficulties assessing the credibility of health information, but requires follow-up to assess whether or not they were able to access and comprehend the information. Previous research suggests that, while most adolescents have access to the Internet, many experience difficulties when trying to locate and understand authoritative information. ${ }^{[20]}$ Text-messaging was also used extensively, by some nurses, to communicate with adolescent patients. Security concerns were raised, however, about this practice. These findings are not unique to our study. In a 2014 review of social media and text messaging in health care, ${ }^{[21]}$ privacy/confidentiality breaches were identified as one of the key themes. Lack of institutional guidelines was another key theme identified. Training and policies that reduce the likelihood of a privacy breach, while maintaining adolescents' timely access to nurses, would help to address these issues.
For effective communication with adolescents, health care providers must, among other things, be able to provide a trustful atmosphere, "treat the adolescent client in a friendly, respectful manner that is empathic, non-judgmental and without discrimination", adapt their communication style, summarize main points, and support parents/guardians in educational tasks (p11). ${ }^{[4]}$ Nurses in our study were acutely aware of the need to provide a trustful atmosphere, and to be respectful, empathic, and non-judgemental. Research with adolescents is needed to determine the extent to which they perceive public health nurses to be respectful, empathic, non-judgmental, and clear in their communication practices. Some, but not all, of the nurses summarized key information for adolescent patients and/or asked adolescents to repeat key information back; provided services to adolescents in schools; or trained peer educators to communicate health information in schools. Uniform uptake of these practices would allow more adolescents to benefit both in the shortand long-term.

Because of our focus on adolescent patients, we did not document the extent to which nurses involved parents/guardians. Adolescents' anxiety/fear of being seen by parents, or others, while attempting to obtain health services did emerge, however, as a prominent patient-related barrier to effective communication. This finding suggests that the involvement of parents/guardians may, in some cases, have detrimental effects. This finding also supports nurses' use of, and the continued need for, tailoured communication approaches that are sensitive to this issue (e.g., business cards, trustworthy websites).

Although novel in its focus, our study has limitations. Interviews were conducted with a small number of female public health nurses providing services to adolescents in one regional health authority. The findings are, therefore, specific to our context and may not reflect the perceptions and communication practices of nurses who: (1) declined participation; (2) work with adolescents in different regions of the province; and (3) are male. Replication is needed with public health nurses working with adolescents in other regions to determine the extent to which their perceptions and practices align with those reported in this study. Bias is another potential limitation. To reduce the likelihood of bias, themes were reviewed and confirmed by all three authors and then compared with the published literature. Despite these limitations, our study is the first, to the best of our knowledge, to describe, with minimal interpretation of the data, public health nurses' perceptions of health literacy in, and related communication practices with, adolescent patients.

Our findings suggest that, without attention to patient- and 
provider-related barriers to effective communication, efforts by public health nurses to promote health literacy in adolescents will be limited. Assessment of public health nurses' health literacy-related perceptions and communication practices can help to identify the type(s) of training and support that are needed, as well as proven strategies (e.g., peer educators and public health nurses in schools) that can be expanded to benefit adolescents in both the short- and long-term.

\section{Conclusion}

Without attention to patient- and provider-related barriers to effective communication, efforts by public health nurses to promote health literacy in adolescent patients will be limited. Identification of patient- and provider-related barriers can help to identify where training and support is needed.
Replication of this study is needed to determine the extent to which the findings align with the perceptions and practices of public health nurses working with adolescents in different settings. Research is needed with adolescents to determine how they: (1) interpret and act on different types of information provided by public health nurses (e.g., written, verbal, digital), (2) assess the communication practices of public health nurses, and (3) prefer to receive information from public health nurses. Research is also needed to determine if, and how, tools designed to help public health professionals integrate health literacy into their daily practice ${ }^{[8,9]}$ address the unique needs of adolescents and the barriers to effective communication identified in this study.

\section{Conflicts of Interest Disclosure}

The authors declare that there is no conflict of interest.

\section{REFERENCES}

[1] World Health Organization. Adolescent development. 2015. Available from: http://www.who.int/maternal_child_adolesc ent/topics/adolescence/dev/en/. Accessed December 28, 2015.

[2] World Health Organization. Health for the World's Adolescents. A second chance in the second decade. 2014. Available from: http://apps.who.int/adolescent/second-d ecade/files/1612_MNCAH_HWA_Executive_Summary.pdf Accessed December 28, 2015.

[3] World Health Organization. Adolescent health epidemiology. 2015. Available from: http://www.who.int/maternal_child_adole scent/epidemiology/adolescence/en/. Accessed December $28,2015$.

[4] World Health Organization. Core competencies in adolescent health and development for primary care providers, 2015. Available from: http://apps.who.int/iris/bitstream/10665/1483 54/1/9789241508315_eng.pdf. Accessed December 28, 2015.

[5] World Health Organization. Track 2: Health literacy and health behaviour. 2015. Available from: http://www. who.int/healthpr omotion/conferences/7gchp/track2/en/. Accessed December 28, 2015

[6] Sanders LM, Shaw JS, Guez G, et al. Health literacy and child health promotion: implications for research, clinical care, and public policy. Pediatrics. 2009; 124: S306-14.

[7] Diamond C, Saintonge S, August P, et al. The development of building wellnessTM, a youth health literacy program. J Health Commun. 2011; 16: 103-18. PMid:21951246. http://dx.doi.org/10.10 $80 / 10810730.2011 .604385$

[8] Nutbeam D. Health literacy as a public health goal: a challenge for contemporary heatlh education and communication strategies in the 21st century. Health Promotion International. 2000; 15: 259-67. http://dx.doi.org/10.1093/heapro/15.3.259

[9] Public Health Association of BC. An inter-sectoral approach for improving health literacy for Canadians, 2012. Available from: http://www.cpha.ca/uploads/portals/h-l/interse ctoral_e.pdf. Accessed May 20, 2016.

[10] Public Health Agency of Canada. HLIT: Health Literacy for Public Health Professionals, 2016. Available from: https://skillsonline.ca/shared/lars/Descriptio nsE/HLT1-Health\%2OLiteracy $\% 20$ for $\% 20 \mathrm{Public} \% 2 \mathrm{Health}$
$\% 20$ Practitioners.pdf?_\&d21SessionVal=. Accessed May $19,2016$.

[11] Centres for Disease Control and Prevention. Health Literacy. Find Training, 2015. Available from: http://www.cdc.gov/healthli teracy/gettraining.html. Accessed May 19, 2016.

[12] Sandelowski M. Whatever happened to qualitative description? Res Nurs Health. 2000; 23: 334-40.

[13] Sandelowski M. What's in a name? Qualitative description revisited. Res Nurs Health. 2010; 33: 77-84.

[14] Crabtree BF, Miller WL. Doing qualitative research. 2nd edition. Thousand Oaks, CA: SAGE Publications; 1999.

[15] Malloy-Weir L. Definitions of adolescent health literacy: A systematic review and critical appraisal. In: Begoray DL, Banister EM, eds. Adolescent health literacy and learning. Hauppauge, NY: NOVA Science Publishers; 2015. p. 13-24.

[16] Gold MA, Kokotailo, PK. Motivational interviewing strategies to facilitate adolescent behavior change. American Academy of Pediatrics. 2007; 20: 1-8. Available from: http://pubs.niaaa.nih.gov/publications/Practiti oner/YouthGuide/AAPAdolescentHealthUpdateBMI . pdf. Accessed May 19, 2016.

[17] Welch J. Building a foundation for brief motivational interviewing: communication to promote health literacy and behavior change. J Contin Educ Nurs. 2014; 45: 566-72. PMid:25401341. http: //dx.doi.org/10.3928/00220124-20141120-03

[18] Channon SJ, Huws-Thomas MV, Rollnick S, et al. A multicenter randomized controlled trial of motivational interviewing in teenagers with diabetes. Diabetes Care. 2007; 30: 1390-95.

[19] Wizowski L, Harper T, Hutchings T. Writing health information for patients and families. Available from: http: //www.hamiltonhealthsciences.ca/workfiles/ PATIENT_ED/Writing_HI_Edition4.pdf. Accessed May 19, 2016.

[20] Skopelja EN, Whipple EC, Richwine P. Reaching and teaching teens: adolescent health literacy and the internet. J Consum Health Internet. 2008; 12: 105-18. http://dx.doi.org/10.1080/15398280802 121406

[21] Basevi R, Reid D, Godbold R. Ethical guidelines and the use of social media and text messaging in health care: a review of the literature. $\mathrm{N}$ Z J Physiother. 2014; 42: 68-80.

ISSN 1925-4040 E-ISSN 1925-4059 